\title{
Incidental Focus on Form and Uptake in Different Proficiency Levels of Iranian Students
}

\author{
Bayan Dastyar \\ English dept. Urmia Branch, Islamic Azad University, Urmia, Iran \\ Mohammad Reza Khodabakhsh \\ English dept. Kurdistan state university, Kurdistan, Sanandaj, Iran
}

\begin{abstract}
This study attempted to add on focus on form discussion by investigating the relationship between complexity of focus on form and u ptake in two proficiency levels of Iranian students. Thus, two different level classrooms were observed and 20 hours of communicative interaction were audio-recorded and transcribed. Chi-square analysis suggested a strong relationship between complexity of focus on form and uptake in lower level students but not in higher level class. Complexity of focus on form did not have relationship with successful uptake in any of the classes. The results support the importance of negotiated interaction in $L_{2}$ development of lower level students.
\end{abstract}

Index Terms - incidental focus on form, complexity, uptake, successful uptake, negotiated interaction

\section{INTRODUCTION}

Meaning- and form-focused instructions are two broad significant approaches to language teaching pedagogy. The former approach is based on the assumptions that learners learn a foreign language when their attention is on communicating meaning rather than on language forms. This approach met with great success at that time and attracted attention of many researchers such as Krashen. It proved that second language learners who had studied in these classrooms were generally more successful commun icators than their peers who participated in traditional form-focused classrooms. Form-focused instruction (FFI) according to Ellis (2001, p.1) refers to "any planned or incidental instructional activity that is intended to induce language learners to pay attention to linguistic form". He believed that this definition of FFI is an umbrella term which covers other definitions such as focus on form, focus on forms (Long, 1991 as cited in Ellis, 2001, p. 2), and analytic teaching (Stern, 1990 as cited in Ellis, 2001, p.2).

There are various classifications of FFI in Second Language Acquisition (SLA) area. One of them belongs to Ellis (2001, p. 14) who distinguished between three types of FFI (a) focus on forms (b) planned focus on form, and (c) incidental focus on form. Focus on forms is a kind of instruction in which learners are provided with pre-selected linguistic items either explicitly or implicitly. It treats students as language learners rather than language users and language is considered an "object" to be studied.

Planned focus on form involves the preselection of several linguistic forms and practicing them intensively. It deals with focused tasks which are specially designed to elicit the use of specific linguistic forms in the context of meaningcentered classrooms. Planned focus on form is similar to focus on forms in that it contains pre-selected linguistic items but their difference lies in their focus. In the former the main focus of instruction remains on conveying meaning while the latter aims to teach specific form of language.

Incidental focus on form, on the other hand, involves no preselection of target form and covers unfocused tasks which are designed to elicit general samples of language rather than concentrating on specific language items. It is claimed (Doughty \& William as cited in Loewen 2005) that the impact of incidental and planned focus on form on learning might vary. That is, planned focus on form enable learners to pay attention to a specific language form intensively while incidental focus on form provides extensive coverage targeting different linguistic forms. The effectiveness of planned focus on form has been investigated by different researchers (Abdolmanafi, 2010; Jahangard, 2010) but only few studies investigated the beneficial effect of incidental focus on form because it is not possible to carry out a pre-test/post-test method to measure its effectiveness which is due to unpredictable nature of incidental focus on form.

According to Loewen (2007, p. 102) the effectiveness of incidental focus on formcan be measured in different ways. One way is to consider uptake. A number of studies (Ohta and Long as cited in Egi, 2010) have argued against the beneficial effect of uptake for SLA on the grounds that uptake is an optional discourse move and cannot be an indication of interlanguage development. Despite such oppositions, the role of uptake in SLA has been supported by different perspectives and theories. For example, interactive perspective which claims that learning a language involves active participation of learners in social interaction. In this regard Long (as cited in Taddarth, 2010) proposed 'interactional hypothesis' based on it interaction and participation in conversation plays an important role in SLA since it "connects input, internal learner capacity and output in productive ways". In addition, negotiation during interaction is 
claimed to be effective in directing the learners' attention to the mis matches between their interlanguage and target language forms. In fact, this hypothesis emphasized the important role of corrective feedback which learners receive during interaction and their own modified output in developing second language learning.

Uptake is a concept which has been defined in different ways. Lyster \& Ranta (1997, p.49) defined uptake based on speech act theory. According to them uptake is "a student's utterance that immediately follows the teacher's feedback and that constitutes a reaction in some way to the teacher's intention to draw attention to some aspects of the student's initial utterance". This definition shows that they have studied uptake only in relation to reactive focus on form, i.e. after a learner produces an erroneous utterance. But Ellis, Basturkmen and Loewen (2001a) claimed that uptake can also occur in pre-emptive focus on form, i.e. after they received information from the teacher or other learners. In the following, different types of uptake are provided.

Example 1: uptake following reactive focus on form

S: Just grown up in Iran. Occupation .... university students. Interests and hobbies... I go ...to... English... She... She is go ...
T: She IS go?
(Reactive focus on form)

S: She goes (uptake)

The above example (example 1) represents the uptake defined by Lyster \& Ranata (1997) because it follows immed iately after the provision of feedback by the teacher.

Example 2: uptake following pre-emptive focus on form

$\mathrm{S}_{1}$ : What's the meaning of politics? (Student-initiated focus on form)

T: who knows politics? Not in Persian please.

$\mathrm{S}_{2}$ : About ....Uh ....some....some...

$\mathrm{S}_{3}$ : About government.

$\mathrm{S}_{2}$ : About government of a country. They have some programs to do..... for the election.

$\mathrm{T}$ : Uh ....mh m. Talking about presidents, leader, the problem of government. All of these are politics.

$\mathrm{S}_{1}$ : aha. (Uptake)

Example 2 represents the uptake defined by Ellis, et al (2001a). As it can be seen, the exchange move preceded by uptake contains an explanation provided by the teacher rather than corrective feedback.

Ellis, et al (2001a, p.295) categorized uptake into different kinds based on type of focus on form. For example, he distinguished three types of uptake in reactive focus on form:

1) Acknowledge: when the learner who initially produced erroneous utterance accepts the feedback provided by the teacher or other students by saying yes.

2) Repair: the learner who produced the erroneous utterance produces the target feature correctly after feedback

3) Needs repair: the learner who produced the erroneous utterance uses the target feature incorrectly.

And uptake in pre-emptive focus on form was divided into three types including:

1) Recognize: in which students acknowledge the information received by expressing $m m$, oh, ahah.

2) Apply: When the student attempts to use the information they received by giving an example or rephrasing.

3) Needs-application: when the students fail to demonstrate understanding the information e.g. the students say something that shows lack of understanding or repeat what the teacher says.

Ellis, et al (2001a), then distinguished between successful and unsuccessful uptake based on the above mentioned classifications. According to him successful uptake is a move in which a student correctly repaired an erroneous utterance or clearly demonstrated understanding of a linguistic item. Unsuccessful uptake refers to the move in which no attempt is made to repair the incorrect form or the student's attempt to repair fails or he fails to clearly demonstrate understanding of the target feature. Based on these definitions successful uptake refers to apply and repair types of uptakes.

One of the rare studies that investigated the effectiveness of incidental focus on form on second language learning was carried out by Loewen (2005).He used an individualized, student specific post-test to measure the effectiveness of incidental focus on form. His results showed that learners were able to recall the targeted linguistic information correctly $60 \%$ of the time one day after the focus on form episodes and $50 \%$ of the time two weeks after focus on form episodes. The findings of this study also showed that among the various characteristics of incidental focus on form, successful uptake was an important predictor of correct test scores.

Alcon Soler \& Garcia Mayo (2008) examined the role of FonF in language learning of 12 Spanish students. Their data included audio-recording of seventeen sessions of teacher-led interaction in English as a compulsory course class, 204 diary entries reporting ite ms noticed items, 204 post-test translations and 204 delayed post-test translations which were created based on what learners claimed to have noticed in their diaries. They found 459 FFEs in their data, i.e. there was one episode in every 0.6 minutes. These findings showed that out of 459 FFEs only $34.2 \%$ led to uptake. The frequency of uptake in this study, was higher in student-initiated $(82.9 \%)$ than teacher-initiated FonF (8.9\%). A mount of uptake also differed in reactive FonF depending on the init iator of feedback. These find ings revealed that uptake was much higher in reactive student supplier $(75.0 \%)$ than in reactive teacher supplier $(8.9 \%)$. The researchers stated that another factor that seemed to have influence on the rate of uptake was complexity of interaction, although it was not considered in their study. Results of Pearson product-moment correlation showed a positive relationship between 
noticing and uptake and a degree of relationship between uptake and immediate post-test. In contrast, the same statistical test shows no correlation between noticing and delayed post-test or uptake and delayed production. They concluded that incidental FonF plays a role in noticing and uptake which in turn are as sociated with short-term learning.

Gholami \& Farrohki (2008) also studied the effectiveness of incidental focus on form in relation to uptake. They found $641 \mathrm{LREs}$ in twenty hours on interactions, i.e. one episode every 1.9 minutes. The nu mber of LREs in both level 4 and 5 were 334 and 307 respectively which demonstrate a slight difference between the two classes. Regarding the frequency of reactive/pre-emptive FonF the results showed the higher rate of pre-emptive FonF than reactive one and Chi-square analysis shows a significant difference in the frequency distribution of reactive and pre-emptive FonF. These results also revealed a low frequency of uptake in this study. They reported that learners reacted to LREs verbally only in $15.2 \%$ of the cases. And because of this low frequency of uptake, they provided the concept of 'camouflaged' which referred, in their study, to non-verbal behavior of learner in response to LREs. Also, there wasn't significant difference in the amount of uptake in two classes. Regarding type of FonF and uptake the results showed that uptake following reactive episodes was much higher than Pre-emptive episodes. In fact, the findings of this study found no significant relationship between type of focus on form and uptake. The researchers concluded that incidental focus on form is frequently used in Iran ian meaning-based EFL classes and their frequency and characteristics vary considerably. They claimed that the variation in the findings of this study in comparison with previous similar studies may be due to the role of instructional context.

Ghafar Samar \& Shayestefar (2009) carried out a quasi-experimental research in which they investigated the occurrence of reactive focus on form and uptake in two communicative classrooms. They also studied the communicative strategies which the students use during interaction to facilitate negotiation. Participants were selected from a public high school in Isfahan, Iran. Totally, 240 minutes of five week lessons were audio recorded. Participants were divided into two Experimental (EXG) and control groups (CG).The result of the study showed a total rate of one FFE every 1.54 minutes. The most frequent type of feedback in this study was metalinguistic (almost 30\%) which constituted one-third of the total reactive focus on form. The second frequent type of feedback was recast (28\%) followed by clarification request $(23.08 \%)$, repetitions $(7.40 \%)$ and elicitation $(4.30 \%)$. Regarding the effect of reactive focus on form on learners' development of commun icative strategies, the results of the study showed that EXG learners focused more on negotiations of both form and meaning. This rate was much lower for CG learners and chi-square analysis revealed a significant difference between CG and EXG in their use of negotiation strategies with higher rate in EXG. The most frequently used type of strategy in EXG and CG was request for clarification but it wasn't as frequent in CG as that of EXG and the difference between them was significant. Findings showed that whereas learners in EXG monitored and self-corrected their erroneous utterance, CG learners did not monitor their output that much. Request for clarification and language switch were used more frequently than other strategies in CG. Looking at the EXG results shows that most of recast moves led to no-uptake $(42.5 \%)$ and only $38 \%$ of the total recast moves led to uptake. Metalinguistic and explicit corrections were the two most successful feedbacks which led to successful uptake (52\% and $45 \%$ respectively) with metalinguistic feedback more successful at eliciting repair. Clarification request and elicitation were similar at promoting uptake, i.e. they both led to uptake $18 \%$ of repairs although elicitation leads to topic continuation $19 \%$ of the time but the rate is $23 \%$ for clarification requests. The researchers claimed that learners in EXG used communication strategies similar to those used by their teacher and it was proved in this study that learners in EXG were significantly different in their emp loy ment of negotiation devices when compared with learners in CG. The researchers of this study claimed that the results of this study emphasized the role of incidental focus on form specifically reactive FonF in drawing learners' attention to linguistic elements during meaning-focused interaction; however, these results should be interpreted cautiously.

Reviewing the above mentioned studies alludes that only few studies have tried to examine the relationship between characteristics of incidental focus on form and uptake. Therefore, the present study aims to investigate the relationship between complexity of focus on form, uptake and successful uptake in two different proficiency levels of Iranian students.

\section{METHODOLOGY}

\section{A. Design of the Study}

A qualitative research design was used for the purpose of this study. Two different level classes from Safir Institute, Sanandaj, Iran were selected and observed over almost three weeks. This Institute is considered a popular private language center all over Iran which has different branches in other cities of Iran. The reason for the selection of this Institute was that methods of language teaching are completely communicative and their primary goal is to teach learners to communicate in foreign language.

\section{B. Participants}

Students of two different level classes from a private language institute were selected as participants of the study. The first class which was pre-intermediate level, consisted of 15 students and their age ranged between 17 to 24 and the second class was an intermediate level consisted of seven students and their age ranged between 16 to 23 years .Except for a few students all learners shared Kurdish as their first language. In order to reduce the effect of different teacher's 
method of teaching on the results of the study one non-native female teacher participated in this study. She was 28 years old and had been teaching English at different private Institutes in Sanandaj for 4 years. She was an M.A student of English literature at Islamic A zad University of Sanandaj.

\section{Instruments/Materials}

The two classes studied Interchange book 2 and 3. They were selected for these levels of proficiency by Safir's authorities. These books covered a variety of activities such as listening, speaking, writing, reading, conversation, discussion, word power, grammar focus and pronunciation practice. In addition, the Safir Institute provided learners with other activities in the classes. For example, watching movies and storytelling. They also studied Oxford Word Skill as their supplementary book. Since the aim of this study was to investigate the characteristics of incidental focus on form, the researcher did not select specific tasks or activities for the study. The materials of this study included natural communicative activities which happened in the classes.

\section{Procedure}

Totally, 24 hours of interaction were observed and audio-recorded by one MP3 wireless recorder. Twelve hours of interaction for each class was collected during three weeks. To obtain necessary and related data, some focus on forms activities and focus on pre-targeted activities such as grammar focus, pronunciation practice and those part of instruction during which learners watched movie or listened to CDs were excluded from data. Finally, 10 hours of mean ing-oriented activities per each class were considered the main data of this research. In order for the data to be as natural as possible the researcher did not explain about the research topic to the teacher or to the students. The main data consisted of 20 hours of audio-recorded interaction from two different proficiency levels of students.

\section{E. Data Analysis}

For the purpose of analysis 20 hours of audio-recorded interaction were listened to carefully twice and all focus on form episodes (FFEs) were identified after the second listening. FFE was defined by Ellis et al (2001a) as "the discourse from the point where the attention to linguistic form starts to the point where it ends". Subsequently, all FFEs were coded for the type of focus on form. Although the purpose of this study was to investigate the complexity of FFEs, the researcher of this study categorized all the FFEs as reactive/pre-emptive FFEs in order to be able to identify the episodes and the uptake moves more easily. Reactive focus on form refers to the corrective feedback provided by either the teacher or other learners. In pre-emptive FoF there is a shift from communicative activity to language forms which are perceived to be problematic even though no actual error occurs. Pre-emptive focus on form was also divided into student-initiated and teacher-initiated focus on form. In the next step, data was analyzed in details and were coded in terms of complexity. Based on the Ellis's (2001a) definition complexity is the length of exchanges, i.e. 'complex' focus on form refers to those which involve several exchanges and 'simple' focus on form refers to those involving a single exchange.

Subsequently, the audio-recorded data were analyzed to identify and transcribe uptake moves. The researcher of this study adapted Ellis's definition of uptake according to which it can occur following pre-emptive focus on form in addition to reactive one. Example 1 also shows the uptake move in a complex FFE. Those episodes in which learners knew the answer of questions, as well as those episodes in which lea rners did not have opportunity to produce uptake were not considered uptake move and were excluded from data analysis. Also, in reactive focus on form those episodes in which the student's errors did not receive feedback and those episodes which contained topic continuation and there was no opportunity for producing uptake were deleted in analysis. And the last step was to code for uptake types which was based on Ellis's classification.

\section{RESULTS}

Results of this study are provided in terms of a) Total amount of FFEs including frequency and percentage of FFEs in both classes b) Total amount of FFEs in terms of complexity including frequency and percentage of complex episodes in both classes c) total amount of uptake in relation to comple xity of FFEs including frequency and percentage of uptake in both classes and d) total amount of successful uptake in relation to complexity of FFEs involving frequency and percentage of successful uptake in pre-intermediate and intermediate classes.

\section{A. Total Amount of FFEs}

Results of the study showed a total a mount of 432 FFEs in the 20 hours of audio-record ing data, with slightly more in the pre-intermediate $(221,51.15 \%)$ than the intermediate class $(211,48.84 \%)$. That is, the overall rate was one FFE, every 2.7 minutes. Table 1 displays amount of FFEs in total and in each class. 
TABLE 1:

FREQUENCY AND PERCENTAGE OF FFES IN TOTAL AND BOTH CLASSES

\begin{tabular}{|l|l|l|}
\hline Proficiency le vel & fre quency & Percentage \\
\hline Pre-intermediate & 221 & $51.15 \%$ \\
\hline intermediate & 211 & $48.84 \%$ \\
\hline total & $\mathbf{4 3 2}$ & \\
\hline
\end{tabular}

In a similar study, Ellis (2001a) identified a total of 448 FFEs in the 12 hours of communicative classrooms, an overall rate of one FFE every 1.6 minutes. Gholami \& Farrokhi (2008) in their study also identified 641 Language Related Episodes (LRE) in the 20 hours of meaning-focused lessons. This means one LRE every 1.9 minutes. The overall rate of one FFE every 2.7 minutes happened in the present study is a much lower rate compared to the above mentioned studies which showed that focus on form did not happened frequently in the observed classes.

\section{B. Total Amount of FFEs in Terms of Complexity}

The identified FFEs were coded in terms of their complexity. The results of the frequency of complex FFEs in total and in each class are presented in Table 2. Out of 432 FFEs only 146 (33.79\%) cases were coded as complex FFEs and most episodes $(286,66.20 \%)$ were simple FFEs.

TABLE 2

FREQUENCY AND PERCENTAGE OF FFES IN TERMS OF COMPLEXITY

\begin{tabular}{|l|l|l|l|}
\hline Proficiency le vel & $\begin{array}{l}\text { Fre quency \& percentage of } \\
\text { complex FFEs }\end{array}$ & $\begin{array}{l}\text { Fre quency \& percentage of } \\
\text { simple FFEs }\end{array}$ & Total amount of FFEs \\
\hline Pre-intermediate & $74(33.48 \%)$ & $147(66.51 \%)$ & $221(51.15 \%)$ \\
\hline intermediate & $72(34.12 \%)$ & $139(65.87 \%)$ & $211(48.84 \%)$ \\
\hline total & $146(33.79)$ & $286(66.20 \%)$ & 432 \\
\hline
\end{tabular}

Table 2 shows that the proportion of complex FFEs in pre-intermediate and intermediate classes were almost similar, with slightly more in intermediate class $(33.48 \%$ and $34.12 \%$ respectively). Also, the frequency of simple FFEs in preintermediate $(66.51 \%)$ and intermediate classes $(65.87 \%)$ were almost the same. Generally speaking, there was no significant difference between low and high proficiency level students regarding the frequency of complex and simple FFEs.

\section{Complexity of FFEs and Uptake}

Results of the frequency and percentage of uptake in both classes are presented in tables 3 and 4 respectively. Overall, there was a total of 432 FFEs in the 20 hours of communicative interactions in two classes (see Table 1). Uptake was possible in $321(74.30 \%)$ of them.

a) Complexity of FFEs and uptake in pre-intermediate class

As table 3 displays, most of FFEs (both simple and complex FFEs) in low level class have led to uptake.

TABLE 3

COMPLEXITY AND UPTAKE IN PRE-INTERMEDIATE LEVEL CLASS

\begin{tabular}{|l|l|l|l|l|}
\hline \multicolumn{3}{|c|}{} & uptake & Total \\
\hline \multirow{3}{*}{ complexity } & \multirow{3}{*}{ Complex } & Frequency & 63 & 74 \\
\cline { 3 - 5 } & & Percentage & $85.1 \%$ & $33.48 \%$ \\
\cline { 3 - 5 } & \multirow{3}{*}{ simple } & Std.Residual & 1.0 & \\
\cline { 3 - 5 } & & Frequency & 103 & 147 \\
\cline { 3 - 5 } & & Percentage & $70.1 \%$ & $66.51 \%$ \\
\cline { 3 - 5 } & & Std.Residual & -.7 & 221 \\
\hline \multirow{2}{*}{ Total } & Frequency & 166 & $51.15 \%$ \\
\cline { 3 - 5 } & & percentage & $75.1 \%$ & \\
\hline
\end{tabular}

Table 3 shows the amount of uptake following complex and simple FFEs in pre-intermediate class. As displayed in this table, out of $74(33.48 \%)$ complex FFEs, 63(85.1\%) led to uptake in this class. Simple FFEs promoted uptake in $103(70.1 \%)$ of cases. Although most of simple FFEs led to uptake move, this rate is much lower compared to uptake following complex FFEs. That is, complex FFEs were more successful than simple FFEs in promoting uptake in preintermediate level class. Table 3 also shows the Std. Residuals value for both complex and simple FFEs. In complex FFEs Std.Residual is positive for uptake (1). That is to say, the frequency of uptake is high in complex FFEs for preintermediate level students. The opposite pattern can be seen for the simple FFEs where learners produced less uptake and Std. Residual is negative for uptake move(-.7). This shows that the rate of uptake following simple FFEs are below expectation.

b) Complexity of FFEs and uptake in intermediate level class

Table 4 indicates the results of uptake in the intermediate level class. The amount of uptake in both simple and complex FFEs is higher than no uptake move. That is, most of FFEs promoted uptake regardless of their complexity . However, the results show that the rate of uptake following complex FFEs is higher than simple focus on form episodes. 
TABLE 4.

COMPLEXITY OF FFES AND UPTAKE IN INTERMEDIATE LEVEL CLASS

\begin{tabular}{|c|c|c|c|c|}
\hline & & & uptake & Total \\
\hline \multirow{6}{*}{$\begin{array}{l}\text { Complexity of } \\
\text { FFEs }\end{array}$} & \multirow{3}{*}{ Complex FFEs } & Frequency & 57 & 72 \\
\hline & & Percentage & $79.2 \%$ & $79.1 \%$ \\
\hline & & Std.Residuals & .6 & \\
\hline & \multirow{3}{*}{ Simple FFEs } & Frequency & 98 & 139 \\
\hline & & Percentage & $70.5 \%$ & $70.5 \%$ \\
\hline & & Std.Residuals & -.4 & \\
\hline & \multirow{2}{*}{ total } & frequency & 155 & 211 \\
\hline & & percentage & $73.5 \%$ & $48.84 \%$ \\
\hline
\end{tabular}

Comparing these findings with the amount of uptake in low level class (See Table 3) also shows that uptake following complex episodes occurred more $(85.1 \%)$ in low level class than high level class $(79.2 \%)$. The table also shows that Std. Residuals (.6) is positive for complex FFEs and negative for simple episodes (-.4). However, despite the differences observed in the table, the result of chi-square shows that the above mentioned differences are not statistically significant, $\chi^{2}=1.40(1 \mathrm{df}, \mathrm{P}=.223>.05)$.

\section{Complexity of FFEs and Successful Uptake}

a) Complexity of FFEs and successful uptake in pre-intermediate level class

Table 5 displays the frequency and percentage of successful uptake in low level class. The total amount of successful uptake in this proficiency level is $100(60.2 \%)$. This shows that most of the uptake moves occurring in this class, regardless of the complexity of FFEs, were successful and only $39.8 \%$ of them were considered unsuccessful uptake.

TABLE 5

AMOUNTOF SUCCESSFUL UPTAKE IN PRE-INTERMEDIATE CLASS

\begin{tabular}{|c|c|c|c|c|c|}
\hline & & & \multicolumn{2}{|c|}{ Type of uptake } & \multirow{2}{*}{ Total } \\
\hline & & & successful & unsuccessful & \\
\hline \multirow{6}{*}{ complexity } & \multirow{3}{*}{ Complex } & Frequency & 38 & 25 & 63 \\
\hline & & Percentage & $60.3 \%$ & $39.7 \%$ & \\
\hline & & Std.Residuals & .0 & .0 & \\
\hline & \multirow{3}{*}{ simple } & Frequency & 62 & 41 & 103 \\
\hline & & Percentage & $60.2 \%$ & $39.8 \%$ & \\
\hline & & Std.Residuals & .0 & .0 & \\
\hline \multirow{2}{*}{\multicolumn{2}{|c|}{ Total }} & Frequency & 100 & 66 & 166 \\
\hline & & percentage & $60.2 \%$ & $39.8 \%$ & \\
\hline
\end{tabular}

With regard to the amount of successful uptake in relation to the complexity of FFEs, the results show that most of the complex FFEs $(60.3 \%)$ led to successful uptake. Also, as displayed in Table 5 most of the uptake moves in simple FFEs $(60.2 \%)$ were successful and only $39.8 \%$ of them were not successful. Therefore, it can be concluded that the percentage of successful uptake in complex and simple FFEs is almost the same $(60.3 \% \& 60.2 \%$ respectively) in preintermediate level students and no difference can be observed between complex and simple episodes regarding successful uptake. Results of Chi-square analysis indicated that there is not any significant relationship between the comple xity of FFEs and successful uptake in pre-intermediate students, $\chi^{2}=.000(1 \mathrm{df}, \mathrm{P}=1>.05)$.

b) Complexity and successful uptake in intermediate level students

Table 6 displays the frequency, percentage and Std.Residual of successful uptake in intermediate level students. As this table shows the percentage of successful uptake following complex FFEs (50.9\%) is lower than successful uptake following simple FFEs $(58.2 \%)$.

TABLE 6:

AMOUNT OF SUCCESSFUL UPTAKE IN INTERMEDIATE CLASS

\begin{tabular}{|c|c|c|c|c|c|}
\hline & & & \multicolumn{2}{|c|}{ Type of uptake } & \multirow{2}{*}{ Total } \\
\hline & & & successful & unsuccessful & \\
\hline \multirow{6}{*}{ complexity } & \multirow{3}{*}{ complex } & Frequency & 29 & 28 & 57 \\
\hline & & Percentage & $50.9 \%$ & $49.1 \%$ & \\
\hline & & Std.Residual & -.5 & .5 & \\
\hline & \multirow{3}{*}{ simple } & Frequency & 57 & 41 & 98 \\
\hline & & Percentage & $58.2 \%$ & $41.8 \%$ & \\
\hline & & Std.Residual & .4 & -.4 & \\
\hline \multirow{2}{*}{\multicolumn{2}{|c|}{ Total }} & Frequency & 86 & 69 & 155 \\
\hline & & percentage & $55.5 \%$ & $44.5 \%$ & \\
\hline
\end{tabular}

As this table shows, the Std.Residual in complex FFEs is negative for successful uptake (-.5) which means that the frequency of successful uptake following complex episodes is very low. On the other hand, the opposite pattern can be 
seen for simple FFEs where the Std.Residual is positive for successful uptake (.4) and negative for unsuccessful uptake $(-.4)$. Based on this table the frequency and percentage of successful and unsuccessful uptake following co mplex FFEs are rather close $(50.9 \% \& 49.1 \%$ respectively) and there is no difference between them and this resulted in the nonsignificant chi-square. The results of this test indicate that there is not any significant relationship between the complexity of FFEs and successful uptake in high proficient learners, $\chi 2=.50(1 \mathrm{df}, \mathrm{P}=.47>.05)$.

\section{DISCUSSION}

The purpose of the present study was to investigate any possible relationship between complexity of incidental focus on form and uptake in two different proficiency levels of Iranian students. Totally, 432 FFEs were identified in the 20 hours of communicative interaction. The proportion of FFEs in pre-intermed iate and intermediate classes was 221 and 211 respectively. This proportion shows a slight difference between the two classes. The overall rate of FFEs was one every 2.7 minutes. In a similar study Ellis, Basturkmen and Loewen (2001a) identified 448 FFEs in 12 hours of interaction in an EFL context. There was FFEs at a rate of every 1.6 minutes. Also, Gholami \& Farrokhi reported 641 Language Related Episodes (LREs) in the 20 hours of meaning-based classroom interaction, a rate of one LRE every 1.9 minute.

In the present study, the occurrence of incidental focus on form was not as frequent as the above mentioned st udies. In addition, it shows an outstanding difference between the occurrence of incidental focus on form in th is study and the similar previous studies. One reason for infrequent use of incidental focus on form, perhaps, is the highly communicative nature of these classes where attention to form is not recommended and the main aim of the classes is to develop communicative abilities of learners. In that case, it seems necessary for language school authorities to offer more training courses to their teachers and introduce the instructional value of focus on form discussion.

According to Mackey et al (as cited in Farrokhi,F.,\& Rahimpour, M., 2011, p. 152) teachers' experience is another important factor which has influence on teachers' use of focus on form in their classrooms. Results of their study indicated that experienced teachers used more incidental focus on form than inexperienced teachers.

The findings of this study revealed that the overall amount of uptake was high in this study. This rate indicates that learners of both classes produced uptake in $74.5 \%$ of the cases. The proportion of uptake in pre-intermediate and intermediate level students was $75.1 \%$ and $73.5 \%$ respectively. This means that there was no difference between the two classes regarding overall number of uptake. This may be due to the fact that the teacher of this study used the same techniques of focus on form in both classes and she did not pay attention to the learners' ability to notice the feedbacks during reactive FFEs or understand the information provided to them during pre-e mptive FFEs.

The first research question in this study was to investigate any possible relationship between one feature of incidental focus on form (complexity) and uptake in low level students. Out of 221 FFEs in pre-intermediate class, $33.4 \%$ FFEs were coded as complex and $66.5 \%$ were considered simple. In this regard, these findings are in line with Ellis's (2001a, p.303) study in which there were 80 complex FFEs out of 429 ep isodes. With regard to the amount of uptake following complex FFEs, Table 3 shows that, as was expected, complex episodes led to higher amount of uptake than simple episodes in lower proficiency level. Although, the percentage of complex FFEs was lower in pre-intermediate level class, most of them $85.1 \%$ were successful in promoting uptake in students of this level of proficiency. The results of chi-square analysis indicated a significant relationship between complexity of focus on form and uptake in lower level students. These findings are completely in line with previous studies such as Ellis (2001a) and Alcon- Soler (2009). Ellis (2001a) in his study found that one of the characteristics of incidental focus on form which affected the production of uptake was the complexity of focus on form. Alcon-Soler (2009) also gained similar results regarding the influence of certain features of incidental focus on form on learners' uptake. She found that the type of feedback and complexity of negotiation were two characteristics of incidental focus on form which were effect ive at promoting uptake. Results on Pears on product-moment correlation indicated a positive relationship between type of feedback and co mplexity. The reason for the influence of complex FFEs on learner uptake perhaps is the role of negotiation in L2 development.

The value of negotiation and its effect on the development of interlanguage has been supported by different researchers such as Nassaji (2007). He examined the potential role of negotiation in an ESL classroom. His findings revealed that feedback that involved extended negotiation resulted in more successful repair of the erro rs by the learners and their peers during interaction than feedback with limited negotiation. In addition, feedback with negotiation resulted in more correction of the errors on the final error correction test by the same student who made the original errors than feedback with no negotiation.

The second research question addressed the extent to which uptake was successful in this proficiency level students. The overall rate of successful uptake, regardless of complexity of FFEs, was high $60.2 \%$ in lower level students which shows that most of uptake moves were successful. However, the rate of successful uptake following complex and simple episodes was almost the same $(60.3 \%$ and $60.2 \%$ respectively). The results of chi-square test indicated any significant relationship between comple xity of FFEs and successful uptake in this level of proficiency.

Although, the results of this study on the difference between uptake following complex and simple focus on form was in line with previous similar study such as Ellis (2001a) and Loewen (2004) but these findings are in contrast with the above mentioned studies regarding successfulness of uptake moves. Ellis (2001a) found that $89.7 \%$ of uptake moves following complex episodes were successful while $69.9 \%$ of simple FFEs led to successful uptake. Also Loewen 
reported that complex FFEs were twice more likely to contain successful uptake than were simple FFEs. These differences may be justifiable on the grounds of learning context. Ellis and Loewen's studies were carried out in ESL context where learners study English as their second language; therefore, they are more proficient than EFL students. The equal percentage of successful uptake following complex and simple FFEs in low level class shows that although complexity of episode is one of the features of incidental focus on form which leads to high amount of uptake but successfulness of uptake does not depend on this characteristic of focus on form. Detailed analysis of transcribed data revealed that explicitness of feedback or information provided to students seems to be more important in successfulness of uptake in low proficiency level students. This finding is supported by Nassaji (2010) who investigated the role of learners' proficiency level students in the effectiveness of incidental focus on form. His findings revealed that learners benefited differently from focus on form depending on their level of proficiency so that as learners' proficiency level increased the effectiveness of incidental focus on form also increased. The third research question dealt with the relationship between the complexity of FFEs and uptake in students with higher proficiency level. The researcher of the study tried to find out whether the proficiency level of the students had any effect on the relationship between this feature of focus on form and uptake. The findings of this research question showed that as with the first research question, the frequency and percentage of uptake following complex FFEs were higher 57, 79.2\% than uptake following simple episodes $98,70.5 \%$. This shows that in complex episodes, the percentage of uptake increased from $70.5 \%$ to $79.2 \%$. However, the results of chi-square analysis revealed that the above mentioned differences are not statistically significant. That is to say, higher proficiency level students of this study benefited almost similarly from simple and complex focus on form ep isodes.

These findings show that higher proficiency level students did not need longer interaction to notice the feedback or information provided by teacher or other students to produce output. Although, Nassaji (2010) measured the effectiveness of incidental focus on form by individualized post-test and based on the ability of learners to notice the teacher's feedback or in formation but uptake is also another way of measuring incidental focus on form which is claimed by different researchers (Ellis 2001; Mackey 2006) to be an indicative of noticing. In this regard, the findings of this part of study support Nassaji's (2010) results which revealed that there was strong relationship between proficiency level and effectiveness of focus on form.

Finally, the last research question addressed the rate of successful uptake and its relationship with complexity of FFEs in higher proficiency students. The findings of this question showed that the rate of successful uptake was higher in simple FFEs than in complex episodes. Based on the results of the previous research question which showed no significant relationship between complexity and uptake in intermediate level students, it is not surprising to find any relationship between complexity and successful uptake at this level of proficiency. This shows that long, complex interactions with extra effort to draw the learners' attention to their erroneous utterances were completely unnecessary for higher proficiency level students of this study. It seems that this feature of incidental focus on form is more useful for low level students because they are not capable of noticing their errors and it seems necessary for teachers to draw the attention of their lower proficient students through using more focus on form techniques.

Results of the present study revealed that incidental focus on form does not occur frequently in Iranian context. The reason for this infrequent use of incidental focus on form may be the teachers' unfamiliarity with focus on form discussion. During the short interview conducted by the researcher of this study with the teacher, it was found that focus on form means grammar teaching or feedback to this teacher. Therefore, it seemed that teachers' belief about focus on form plays an important role in using it.

Considering the important role of incidental focus on form and its different characteristics in drawing learners' attention to linguistic forms and its potential for producing output specifically in lower level students, the most important imp lication of this study is for authorities of private foreign language institutes to offer more training courses to their teachers. It is hoped that EFL teachers' familiarity with the value of incidental focus on form and its different features encourage them to apply it more effectively in their classrooms based on the learners' proficiency level.

Limitation, delimitation and suggestion for further research

Delimitation of this study relates to the selection of students' proficiency level. Intermediate was the highest level of this institute, so the researcher of the present study selected this level as the higher level group. In addition since elementary level classes had different teachers they were not selected as the other group; therefore pre-intermediate level was selected as the lower level class .Limitation of the study is the small nu mber of students.

Findings of this study supported the results of the previous studies and revealed that complexity of FFEs is an important factor in promoting uptake. However, this result was obtained only for pre-intermediate students but not for intermediate class. That is, there was no difference between complexity of FFEs and uptake in the intermediate level class although the rate of uptake following complex episodes was higher than uptake following simple ones. However, because of the limited number of students specifically in intermediate level class it is suggested that future studies remove this limitation to be able to generalize the results of the study. Based on the "information processing" theory proposed by VanPatten (2002) beginner language learners have limited processing capacity and this can influence their ability to notice their errors or the information provided by others in the classroom. Therefore, it seems necessary to investigate the role of more advanced proficiency level in promoting uptake. 
The findings of this study also suggest the investigation of the effectiveness of other characteristics of focus on form in producing uptake in learners with different proficiency levels. More investigation will be necess ary to examine the possible role of learners' factors such as age and gender and etc. in producing uptake and successful uptake. And finally, it is important to find any relationship between uptake and L2 learning in future researches .

\section{CONCLUSIONS}

The present study tried to add to the previous descriptive studies on the role of incidental focus on form in L2 development. These studies measured the effectiveness of incidental focus on form based on the rate of uptake. Some researchers cast doubt on the use of learners' uptake as a yardstick for learning a language on the grounds that uptake is an optional discourse move and cannot be considered an indication of long term learning.

However, some theoretical perspectives such as Swain's Output hypothesis (as cited in Egi, 2010) advocated the beneficial effect of uptake and output on SLA. Most of the previous studies investigated the relationship between reactive/pre-emptive focus on form and only few of them considered the role of characteristics of focus on form in promoting uptake. The results of the frequency and percentage of FFEs showed that incidental focus on form does not happen frequently in Iranian English classrooms.

Other findings of this study are related to the difference between complex and simple FFEs and producing uptake in pre-intermed iate level class. The results of this research question are in line with similar studies; that is, the frequency and percentage of uptake following complex FFEs was higher than this rate in simple episodes. Findings of chi-square analysis indicated a significant relationship between this characteristic of incidental focus on form and uptake in lower proficiency level students. Similar results obtained from higher level class revealed that the rate of uptake following complex FFEs was slightly higher than this rate following simple episodes. However, this difference is not statistically significant and null hypothesis is supported for the third research question.

This finding supported the importance of negotiated interaction in L2 development of low proficiency level students. In this regard Long (1996 as cited in Taddarth, 2010) suggested the 'interaction hypothes is "in which he claimed that "negotiation for meaning, and especially negotiation work that triggers interactional adjustments by the NS or more competent interlocutors, facilitates acquisition because it connects input, internal learner capacities, particularly selective attention and output in productive ways". Based on the findings of this study one can conclude that negotiated interaction is useful for lower students in terms of producing uptake.

It seemed that lower proficient students benefited more from long, complex interaction than higher proficient class in terms of producing uptake because they are not able enough to notice their erroneous utterances at first turns of interactions. Results related to the rate of successful uptake in pre-intermediate class indicated that the overall rate of successful uptake was higher than unsuccessful uptake moves. However, the rate of successful uptake following complex and simple FFEs was almost the same. It was concluded that there is no significant relationship between complexity of FFEs and successful uptake in lower proficient students. This finding revealed that although complexity of incidental focus on form is effective in promoting uptake in lower level students it did not guarantee the success of uptake. It seemed that success of uptake depends more on the other characteristics of focus on form than its complexity.

Results of successful uptake in intermed iate class also revealed that the overall rate of successful uptake was higher than unsuccessful uptake moves, regardless of the complexity of episodes. However, the frequency and percent age of successful uptake indicated that uptake moves were more successful when occurred following simple episodes in this class. Based on the obtained results, it can be concluded that long interaction is effective in drawing less proficient students' attention to their errors and in pushing them to produce output.

This conclusion is supported by Schmidt's $(1990 ; 2010)$ 'noticing hypothes is' which claims that in order for learn ing to take place, learners should notice to linguistic forms in input. This seems to be more significant for lower proficient learners who are not aware of the gaps between their knowledge and the correct target language forms. Therefore, it is necessary to try to draw their attention to linguistic forms during interaction; and this ai m can be achieved by incidental focus on form.

\section{ACKNOWLEDGMENT}

Hereby I would like to express my deepest gratitude to people who accompanied me in this amazing work. My greatest appreciation goes to Professor Khodabakhsh, my supervis or for his continuous and helpful support during the work and for giving me a chance to work with him. His insightful comments and feedbacks greatly help me improve this work. My gratitude goes also to the principal, teacher and learners in Safir Institute in Sanandaj for their kind cooperation and letting me to participate in their classes and to collect my data. This thesis would not have been completed without their kindness and cooperation.

\section{REFERENCES}

[1] Abdolmanafi. S.J. (2010). Effects of focus on form on learning of relative clauses in an EFL Context. MJAL, 2 (1): 27-39. 
[2] Alcon-Soler, E., \& Garcia Mayo, M. (2008). Incidental focus on form and learning outcomes with young foreign language classroom learners. Second Language Acquisition and the Younger learner, Jenefer Philp, Rhonda Oliver and Alison Mackey (eds), 173-192. Amesterdam: John Benjamins.

[3] Egi, T. (2010). Uptake, modified output, and learner perceptions of recasts: learner responses as language awareness. The modern language Journal, 94 (1): 1-21.

[4] Ellis, R. (2001). Introduction: Investigating form-focused instruction. Language Learning, 51 (1): 1-46.

[5] Ellis, R., B asturkmen, H., \&Loewen, S. (2001 a). Learner uptake in communicative ESL lessons. Language learning. 51 (2): 281-318.

[6] Ellis, R., B asturkmen, H., \& Loewen, S. (2001b). Pre-emptive focus on form in the ESL classroom. TESOL Quarterly, 35, 407432.

[7] Farrokhi, F., \& Rahimpour, M. (2011). Incidental focus on form techniques in Iranian EFL classrooms: a comparison between expert and novice teachers. World journal of Education, 1, 1, 150-157.

[8] Ghafar Samar, R., \& Shay estefar,P. (2009). Corrective feedback in EFL classrooms: learner negotiation strategies and uptake. Journal of English Teaching and learning, 212, 108-133.

[9] Gholami, J., \& Farrokhi, F. (2008). Reactive and pre-emptive Language Related Episode and uptake in an EFL class. Iranian EFL journal, 1, 50-83.

[10] Jahangard, A. (2010). Form-focused second language vocabulary learning as the predictor of EFL achievement: A case for translation in a lon gitudinal study. MJAL, 2 (1): 40-75.

[11] Loewen, Sh. (2004). Uptake in incidental focus of form in mean ing-focused ESL lessons. Language Learning, 54 (1): $153-188$.

[12] Loewen, Sh. (2005). Incidental focus on form and language learning. SSLA, 27, 361-386.

[13] Loewen, Sh. (2007).The prior and subsequent use of forms targeted in incidental focus on form. In Fotos, S., \& Nassaji, H (Eds.). Form-focused instruction and teacher education (pp 101-116). Oxford: Oxford University Press.

[14] Lyster, R., \& Ranta, L. (1997). Corrective feedback and learner uptake: Negotiation of from in communicative classrooms. Studies in second language acquisition, 20, 37-66.

[15] Mackey, A. (2006). Feedback, noticing and Instructed second language learning. Applied linguistics, 27,405-430.

[16] Nassaji, H., \& Fotos, S. (2007). Issues in form-focused instruction and teacher education. In Fotos, S., \& Nassaji, H (Eds.), Form-focused instruction and teacher education (pp 7-15). Oxford: Oxford university press.

[17] Nassaji, H. (2010). The occurrence and effectiveness of spontaneous focus on form in adult ESL classroom. The Canadian Modern language Review, 66 (6): 907-933.

[18] Schmidt, R. (1990).The role of consciousness in second language learning. Applied linguistics, 11, 129-158.

[19] Schmidt, R. (2010). Attention, awareness and individual differences in lan guage learning. In W.M. Chan, S. Chi, K.N. Cin, J. Istanto, M. Nagami, J. W. Sew, T. Suthiwan, \& I. Walker, Proceedings Of CLaSIC 2010, Sin gapore, Desember 2-4 (pp. 721 737). Natinal university of Singapore, center for lan guage studies.

[20] Surakka, K. (2007). Corrective feedback and learner uptake in an EFL classroom. a Pro Gradu Thesis , university of JYVÄSKYLÄ, 3-70.

[21] Taddarth, A. (2010). Recast, uptake and learning: effects and relationships. Unpublished M.A Thesis, University of Montreal, Montreal, Quebec, Canada, 1-79.

[22] VanPatten, B. (2002). Processing instruction: An update. Language learning, 52(2): 755-80.

Bayan Dastyar was born in Sanandaj, Iran in 1981. She recently graduated from Azad University of Urmia studied ELT. She received her B.A degree in English lan guage translation in Azad University of Hamedan in 1999.

She worked as a translator in an engineering firm from 2003 to 2004. She is currently an English teacher in private language schools in Sanandaj. From 2008 to 2009 she worked as a translator in Sky com Co.Ltd.

Miss Dastyar is currently an English teacher in private English schools in Sanandaj.

Mohammad Reza Khodabakhsh was born in Sanandaj, a city in the west of Iran in 1957. He received his Mohammad Reza Khodabakhsh was born in Sannandaj, a city in the west of Iran in 1957. He received his PhD in applied linguistics From Allameh Tabatabaie University in 2010, his M.A. in TEFL from the same university in 1993. He received another M.A. in applied linguis tics from Islamic Azad University in Iran in 1990. He got his B.A. from Razi in Iran University in TEFL in 1984.

From 1988 to 2010 he was a Lecturer in TEFL at the University of Kurdistan and since 2010 to date he has been an Assistant Professor at that University. He was also a faculty member of Islamic Azad University of Hamedan from 1988 to 2011 . From 1992 to 2001he was a Lecturer at Islamic Azad University of Malayer. His publications include the following:

"The Impact of Motivation on English Language Achievement" (unpublished research), Transitivity in Persian (2003). Boualisina University. Iran; The Effect of Speech Modification on Listening Comprehension. (2010). The Journal of Foreign Language and Linguistics. Canada. The Effect of Stress, Intonation, and Speed on Listening Comprehension (2011), in the Iranian Journal of TEFL, Mashhad University, Iran.

Dr. Khodabakhsh was the head of English Department at Kurdistan University in 2003. He is currently a member of TELSI in Iran. 